\title{
Verification of surface minimum, mean, and maximum temperature forecasts in Calabria for summer 2008
}

\author{
S. Federico ${ }^{1,2}$ \\ ${ }^{1}$ ISAC-CNR, UOS of Lamezia Terme, Lamezia Terme (CZ), Italy \\ ${ }^{2}$ CRATI, Rende (CS), Italy
}

Received: 5 July 2010 - Revised: 26 November 2010 - Accepted: 17 December 2010 - Published: 16 February 2011

\begin{abstract}
Since 2005, one-hour temperature forecasts for the Calabria region (southern Italy), modelled by the Regional Atmospheric Modeling System (RAMS), have been issued by CRATI/ISAC-CNR (Consortium for Research and Application of Innovative Technologies/Institute for Atmospheric and Climate Sciences of the National Research Council) and are available online at meteo.crati.it/previsioni.html (every six hours). Beginning in June 2008, the horizontal resolution was enhanced to $2.5 \mathrm{~km}$. In the present paper, forecast skill and accuracy are evaluated out to four days for the 2008 summer season (from 6 June to 30 September, 112 runs). For this purpose, gridded high horizontal resolution forecasts of minimum, mean, and maximum temperatures are evaluated against gridded analyses at the same horizontal resolution $(2.5 \mathrm{~km})$.

Gridded analysis is based on Optimal Interpolation (OI) and uses the RAMS first-day temperature forecast as the background field. Observations from 87 thermometers are used in the analysis system. The analysis error is introduced to quantify the effect of using the RAMS first-day forecast as the background field in the OI analyses and to define the forecast error unambiguously, while spatial interpolation (SI) analysis is considered to quantify the statistics' sensitivity to the verifying analysis and to show the quality of the OI analyses for different background fields.

Two case studies, the first one with a low (less than the 10th percentile) root mean square error (RMSE) in the OI analysis, the second with the largest RMSE of the whole period in the OI analysis, are discussed to show the forecast performance under two different conditions. Cumulative statistics are used to quantify forecast errors out to four days. Results show that maximum temperature has the largest RMSE, while minimum and mean temperature errors are similar. For
\end{abstract}

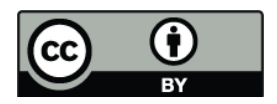

Correspondence to: S. Federico (s.federico@isac.cnr.it) the period considered, the OI analysis RMSEs for minimum, mean, and maximum temperatures vary from 1.8, 1.6, and $2.0^{\circ} \mathrm{C}$, respectively, for the first-day forecast, to $2.0,1.9$, and $2.6^{\circ} \mathrm{C}$, respectively, for the fourth-day forecast.

Cumulative statistics are computed using both SI and OI analysis as reference. Although SI statistics likely overestimate the forecast error because they ignore the observational error, the study shows that the difference between OI and SI statistics is less than the analysis error.

The forecast skill is compared with that of the persistence forecast. The Anomaly Correlation Coefficient (ACC) shows that the model forecast is useful for all days and parameters considered here, and it is able to capture day-to-day weather variability. The model forecast issued for the fourth day is still better than the first-day forecast of a 24-h persistence forecast, at least for mean and maximum temperature. The impact of using the RAMS first-day forecast as the background field in the OI analysis is quantified by comparing statistics computed with OI and SI analyses. Minimum temperature is more sensitive to the change in the analysis dataset as a consequence of its larger representative error.

\section{Introduction}

This paper investigates the performance of the highresolution $(2.5 \mathrm{~km}$ horizontal resolution) operational forecast of minimum, mean, and maximum temperatures issued by CRATI/ISAC-CNR for the Calabria peninsula (Southern Italy, Fig. 1). Temperature forecasts are produced daily by the Regional Atmospheric Modeling System (RAMS; Cotton et al., 2003). The model horizontal resolution was enhanced from 6 to $2.5 \mathrm{~km}$ in June 2008 and this paper shows the forecast performance from 6 June to 30 September 2008 (112 runs out of 117 days because the forecast was not available for 5 days). 


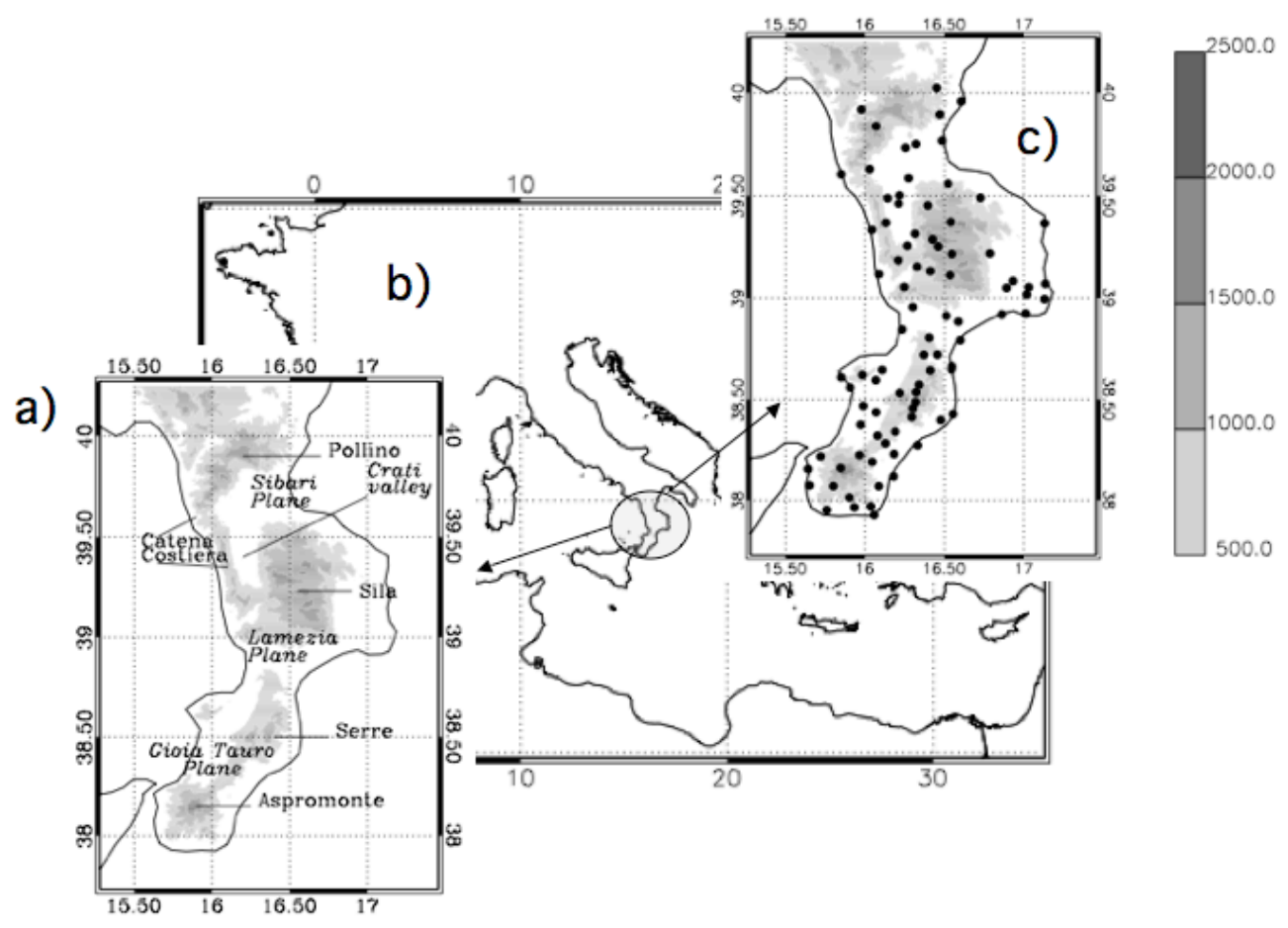

Fig. 1. (a) Calabria features cited into the text; (b) Calabria region and its position in the central Mediterranean; (c) Black-filled circles are the stations of the regional network. Grey shading shows the orographic height $(\mathrm{m})$.

The orography of Calabria is complex for three main reasons (Fig. 1a): the sea-land contrast; mountain peaks with elevations greater than $1000 \mathrm{~m}$ near the shoreline $(<10 \mathrm{~km})$; and, considerable variability of terrain height as a function of location.

All of these physiographic factors cause distinct microclimates and responses to specific weather patterns. Due to the sea-land contrast, a sharp temperature gradient develops across the shoreline and differences of several degrees can be reported between two stations located near the coast and few kilometres inland (Simpson, 1994). It is well known that, when a cold pool develops, differences of several degrees can be reported by two close stations located in a mountain gap and along an adjacent ridge (Myrick et al., 2005; Mass et al., 2003).

These issues have been investigated for Calabria from a climatic perspective (Colacino et al., 1997; Federico et al., 2009) and for case studies (Federico et al., 2008). These studies show the multitude of local climates that characterize the region, as well as the different impact of specific weather patterns in different locations.

It is often assumed by forecast evaluators that observation errors are small enough that comparing forecasts directly with observations can assess forecast accuracy. Nevertheless, observations can develop systematic errors under particular weather conditions due to position, exposure, and instrumental errors (Myrick and Horel, 2006). Even supposing a per- fect instrument, that is, with no observational errors, position is an important issue for regions with complex orography because the model forecast is defined as the average value of the meteorological parameter over the grid box, and is representative of the expected conditions inside the grid box. For example, suppose there is a station located by the sea (lets say $500 \mathrm{~m}$ inland) and its observations are compared with the model forecast for the corresponding grid box. If the grid box contains a portion of sea and a portion of land, the forecast temperature is the weighted average of the value over land and water (weights are equal to the fraction of the area inside the grid box covered by each patch). The two temperatures, depending on meteorological conditions and time of the day, can differ by several degrees, thus directly comparing the forecast with the observation over-penalizes the forecast.

To cope with this issue the forecast is compared with analyses, which are a fundamental part of the CRATI/ISAC-CNR operational temperature forecast because they are used not only for forecast verification, but also as initial data in several agro-meteorological applications (a few of these are available online at http://meteo.crati.it/agrometereologia.html). ${ }^{1}$ As reviewed by Kalnay (2003) and as reported in Myrick

\footnotetext{
${ }^{1}$ Currently the end users of the temperature forecast are the Regional Agency for Environmental Protection (www.cfcalabria.it) and small enterprises interested in the local forecast (farmers and Information and Communication Technology sector).
} 
Table 1. RAMS model setting. NNXP, NNYP and NNYZ are the number of grid points in the west-east, north-south, and vertical directions. $\mathrm{Lx}(\mathrm{km}), \mathrm{Ly}(\mathrm{km}), \mathrm{Lz}(\mathrm{m})$ are the domain extension in the west-east, north-south, and vertical directions. $\mathrm{DX}(\mathrm{km})$ and $\mathrm{DY}(\mathrm{km})$ are the horizontal grid resolutions in the west-east and north-south directions. CENTLON and CENTLAT are the geographical coordinates of the grid centres.

\begin{tabular}{llll}
\hline & First grid & Second grid & Third grid \\
\hline NNXP & 85 & 70 & 68 \\
NNYP & 85 & 70 & 110 \\
NNZP & 30 & 30 & 30 \\
Lx $(\mathrm{km})$ & 2520 & 517.5 & 167.5 \\
Ly $(\mathrm{km})$ & 2520 & 517.5 & 272.5 \\
Lz $(\mathrm{m})$ & 16300 & 16300 & 16300 \\
DX $(\mathrm{km})$ & 30 & 7.5 & 2.5 \\
DY $(\mathrm{km})$ & 30 & 7.5 & 2.5 \\
CENTLAT & 41.5 & 39.2 & 39.0 \\
CENTLON & 12.5 & 16.5 & 16.3 \\
\hline
\end{tabular}

and Horel (2006) "the goal of objective analysis is to minimize the difference between analyses and the unknown truth over a large sample of analyses, given the errors of both the observations and background field from which analyses are derived."

This study does not address the forecast value for a specific application of interest to a specific end-user. It assesses the overall forecast performance for the purpose of strategic planning (the administrative verification forecast; Mason and Weigel, 2009; Joliffe and Stephenson, 2003; Murphy, 1993; Brier and Allen, 1951). In particular: (a) cumulative statistics for the bias and root mean square errors (RMSE) are employed to assess the forecast error out to four days, and; (b) the skill of the RAMS forecast is compared by means of the Anomaly Correlation Coefficient (ACC) against those related to the persistence forecast, which is supposed to have good performance in summer because the Central Mediterranean is characterized by fair and stable weather during this season.

The paper is divided as follows: Sect. 2 provides details of the observations and objective analysis; Sect. 3 examines two case studies to show how the analysis corrects the background field in two different cases and also provides cumulative measure-oriented statistics for assessing common forecast tendencies and forecast errors; and Sect. 4 provides conclusions.

\section{The objective analysis}

\subsection{Observation dataset and background field}

The observation dataset consists of minimum, mean, and maximum temperature from 87 thermometers (Fig. 1)

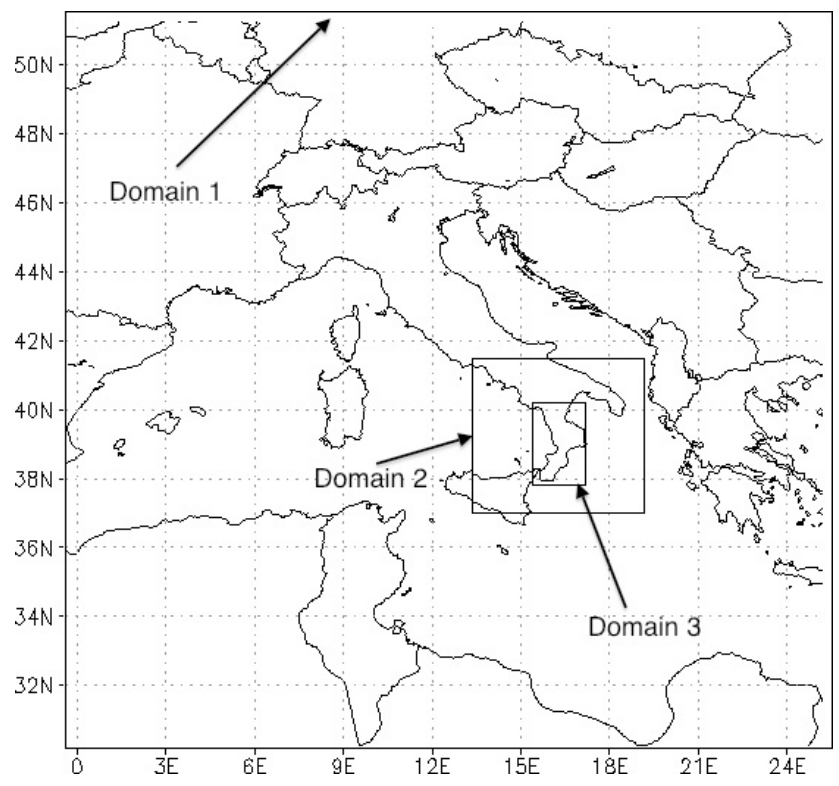

Fig. 2. The three RAMS domains.

provided by the Regional Agency for Environmental Protection of Calabria (ARPACAL). The average minimum distance between two thermometers is $10 \mathrm{~km}$, which is assumed to be the resolution of the database. The spatial distribution of the 87 thermometers is rather homogeneous and covers both mountains and lowlands.

Data are quality controlled by the ARPACAL but, in this study, considerable effort was spent to objectively evaluate the dataset.

The objective methodology generates a time series for each station (target station) and for each parameter (i.e., minimum, mean, and maximum temperatures) by interpolating the records of the surrounding stations within a search radius of $40 \mathrm{~km}$. The weight assigned to each interpolating station is the square of the ratio between the temperature correlation coefficient (computed between the interpolating and the target stations) and its distance from the target station. This functional form gave better performance compared to inverse linear distance, inverse square distance, and Kriging. If the difference between the interpolated value and the original value is larger than the standard deviation of the target station computed for the whole period, the interpolated value replaces the original one. Less than $2 \%$ of the original data were replaced for minimum and maximum temperature and less than $1 \%$ of the original data were replaced for mean temperature.

All the choices in the quality control process outlined above are derived from a study that examines daily minimum, mean, and maximum temperatures from 1994 to 2008 (unpublished work). This study follows a similar technique to that reported in Federico el al. (2009) for precipitation. 
The forecast is issued by the RAMS model (nonhydrostatic), version 6.0. A detailed description of the RAMS model is given in Cotton et al. (2003) while the following is a brief description of the model setup.

Three two-way nested domains with horizontal resolutions of $30,7.5$, and $2.5 \mathrm{~km}$ are used (Table 1, Fig. 2). Thirty vertical levels, up to $16300 \mathrm{~m}$ in the terrain-following coordinate system, are used for all domains. Levels are not equally spaced: layers within the Planetary Boundary Layer (PBL) are between 50 and $200 \mathrm{~m}$ thick, whereas layers in the middle and upper troposphere are $1000 \mathrm{~m}$ thick.

The Land Ecosystem-Atmosphere Feedback model (LEAF, version 3) is used to calculate the exchange between soil, vegetation, and atmosphere (Walko et al., 2000). LEAF is a representation of surface features, including vegetation, soil, lakes and oceans, and snow cover, and their influence on each other and on the atmosphere. LEAF includes prognostic equations for soil temperature and moisture for multiple layers, vegetation temperature and surface water including dew and intercepted rainfall, snow cover mass and thermal energy for multiple layers, and temperature and water vapour mixing ratio of canopy air. Exchange terms in these prognostic equations include turbulent exchange, heat conduction and water diffusion and percolation in the snow cover and soil, long-wave and short-wave radiative transfer, transpiration, and precipitation.

Non-convective precipitation is computed from explicit prognostic equations for seven water categories: cloud particles, rain, pristine ice, snow, aggregates, graupel, and hail (Walko, 1995). The explicit microphysics scheme is applied to all model grids. Convective precipitation is parameterized following Molinari and Corsetti (1985) who proposed a simplified form of the Kuo scheme that accounts for updrafts and downdrafts. The convective scheme is applied to the two outer domains.

RAMS parameterizes the unresolved transport using Ktheory, in which the covariances are evaluated as the product of an eddy mixing coefficient and the gradient of the transported quantity.

The turbulent mixing in the horizontal directions is parameterized following Smagorinsky (1963), which relates the mixing coefficients to the fluid strain rate and includes corrections for the influence of the Brunt-Vaisala frequency and the Richardson number (Pielke, 2002). Vertical diffusion is parameterized according to the Mellor and Yamada (1982) scheme, which employs a prognostic turbulent kinetic energy.

A full-column, two-stream single-band radiation scheme is used to calculate short-wave and long-wave radiation (Chen and Cotton, 1983). The Chen and Cotton scheme accounts for condensate in the atmosphere, but not whether it is cloud water, rain, or ice.

Atmospheric initial and dynamic boundary conditions, available every six hours at $1 \times 1$ degree horizontal resolution, are derived from the 12:00 UTC Global Forecasting
System (GFS) run of the National Centres for Environmental Prediction (NCEP; Sela, 1980, 1982). A four-dimensional data assimilation technique is used to define the forcing at the lateral boundaries of the five outermost grid cells of the largest domain.

The RAMS model is run once a day at CRATI/ISACCNR. The model output is stored hourly. The hourly output is used to compute surface minimum, mean, and maximum temperatures over the RAMS grids. As discussed in the introduction, the forecast is compared with Optimal Interpolation (OI) gridded analyses, to take into account the subgrid-scale variability in weather and positional measurement errors. Surface temperatures over the third RAMS domain for the first-day forecast are used as background in the OI algorithm.

\subsection{The analysis system}

For convenience, this section illustrates some aspects of the objective analysis implemented in the study, which relies on OI (Kalnay, 2003).

The analysed field, that is, the two-dimensional field of minimum, mean, or maximum temperature, is given by the equation:

$\boldsymbol{x}_{\mathrm{a}}=\boldsymbol{x}_{\mathrm{b}}+\mathbf{W}\left[\boldsymbol{y}_{\mathrm{o}}-\mathbf{H}\left(\boldsymbol{x}_{\mathrm{b}}\right)\right]$

where $\boldsymbol{x}_{\mathrm{a}}$ is the analyzed vector (i.e., the best estimate of the unknown "truth"), $\boldsymbol{x}_{\mathrm{b}}$ is the background (or first guess) field, taken from the RAMS first-day forecast (see previous section), $\boldsymbol{y}_{\mathrm{o}}$ is the observational vector, whose elements are the measurements of the 87 thermometers, ${ }^{2} \mathbf{H}$ is the forward observational operator, which converts the background field into first guesses of the observations, and $\mathbf{W}$ is the optimal weight (or gain) matrix.

The gain matrix $\mathbf{W}$ is given by:

$$
\mathbf{W}=\mathbf{B H}^{T}\left(\mathbf{R}+\mathbf{H B H}^{T}\right)^{-1}
$$

where $\mathbf{B}$ and $\mathbf{R}$ are the background and observational error covariance matrices, respectively, and $\mathbf{H}^{T}$ is the transpose of the forward observation operator (which transforms observation points back to grid points).

The $\mathbf{H}$ matrix is a bilinear interpolation operator, which accounts for the altitude differences between grid points and stations. In particular, for each day, the vertical gradient $(\gamma)$ of the minimum, mean, and maximum temperature is computed considering all land grid points of the third RAMS domain (Fig. 2). This gradient is used in the bilinear interpolation operator to account for differences between grid points and station altitudes. The $\mathbf{H}$ operator changes daily for each parameter. The dimensions of the $\mathbf{H}$ matrix are $p \times n$ where $p$ is 87 (the number of thermometers) and $n$ is 7840 (i.e. the number of grid points of the third RAMS domain; Table 1).

\footnotetext{
${ }^{2}$ Before entering the OI scheme, measurements are quality controlled following the procedure presented in Sect. 2.1.
} 


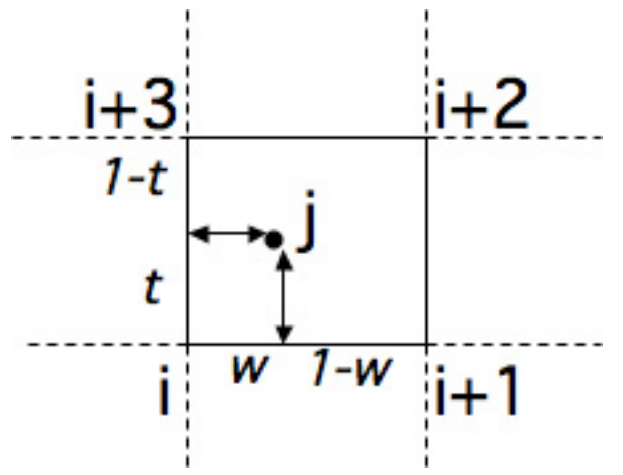

Fig. 3. The $\mathbf{H}$ operator. $i, i+1, i+2$ and $i+3$ are the grid points surrounding the station $j$. The weights $w$ and $t$ are the distances between the station $j$ and grid point $i$ along the $x$ and $y$ directions of the polar stereographic projection used by RAMS.

Referring to Fig. 3, the explicit form of the component $j$ $(j=1, . ., p$ is the station index $)$ of the vector $\mathbf{H} \boldsymbol{x}$ is:

$$
\begin{aligned}
(\mathbf{H} \boldsymbol{x})_{j}= & (1-w)(1-t)\left(x_{i}-\gamma\left(z_{i}-z_{j}\right)\right) \\
& +w(1-t)\left(x_{i+1}-\gamma\left(z_{i+1}-z_{j}\right)\right) \\
& +w t\left(x_{i+2}-\gamma\left(z_{i+2}-z_{j}\right)\right) \\
& +(1-w) t\left(x_{i+3}-\gamma\left(z_{i+3}-z_{j}\right)\right)
\end{aligned}
$$

where $w$ and $t$ are the interpolation weights and $z$ is the altitude.

The $\mathbf{R}$ and $\mathbf{B}$ matrices depend on the observation $\left(\sigma_{o}^{2}\right)$ and background $\left(\sigma_{b}^{2}\right)$ error covariances, respectively, whose magnitudes are estimated by the Lönnberg and Hollingsworth method (Lönnberg and Hollingsworth, 1986; Xu et al., 2001; Myrick and Horel, 2006). The covariance between observational innovations $\boldsymbol{y}_{o}-\mathbf{H} \boldsymbol{x}_{b}$ is computed as a function of the distance $r$ from all background field-observation pairs:

$\operatorname{cov}(r)=\overline{\left(o_{i}-b_{i}\right)\left(o_{j}-b_{j}\right)}$

where $o$ is the measurement, $b$ is the background field interpolated at the station point, $i$ and $j$ are indices denoting the stations $(i=1, \ldots, p ; j=1, \ldots, p)$, and the overbar is the average operator. We assume that: (a) the observational errors are uncorrelated with one another; and (b) the background and the observational errors are uncorrelated. With these assumptions, Eq. (3) becomes:

$\operatorname{cov}(r=0)=\sigma_{o}^{2}+\sigma_{b}^{2}$

and:

$\operatorname{cov}(r \neq 0)=\sigma_{b}^{2} \rho(r)$

where $\rho(r)$ is the background error correlation, which is assumed as an isotropic function of the distance.

Figure 4 shows the covariance of the observational innovation as a function of $r$ for minimum, mean, and maximum temperatures. The covariance drops sharply with $r$, however

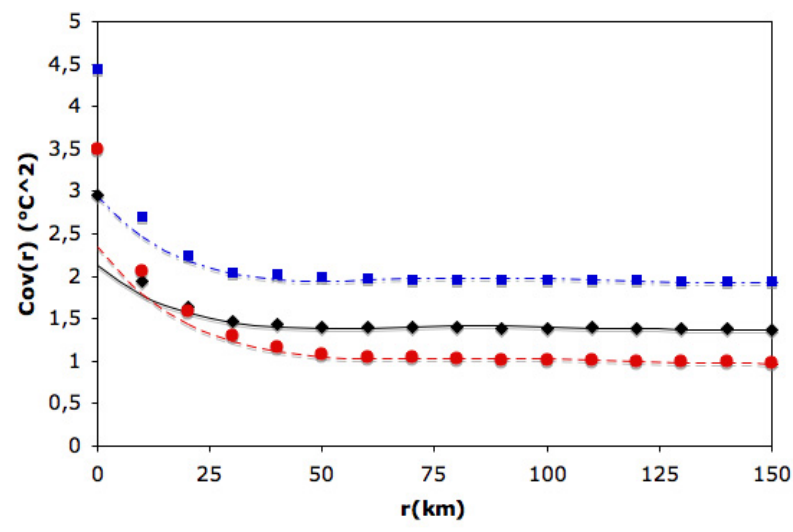

Fig. 4. Binned innovation covariance for minimum (squares), mean (diamonds), and maximum (circles) temperatures. The curves (dotdash, solid, and dash for minimum, mean, and maximum temperatures) are 6th order polynomial fittings of the binned covariances.

it remains almost constant for distances greater than $100 \mathrm{~km}$, showing that errors remain correlated for long distances. The data fitting, binned every $5 \mathrm{~km}$, is given by a sixth-order polynomial. This order was chosen, among polynomials from second to the tenth degree, because it minimized the $\chi^{2}$ of the interpolating polynomial (Press et al., 1992, Chapter 15). It should also be emphasized that estimates of $\sigma_{b}^{2}$ and $\sigma_{o}^{2}$ differ by less than $0.5^{\circ} \mathrm{C}$ for polynomial fittings from the fifth to the tenth degree.

Extrapolating the polynomial fitting to $r=0$ gives the estimate of the background error covariance $\sigma_{b}^{2}$. The difference between the total covariance for $r=0$ and the background error covariance $\sigma_{b}^{2}$ gives the observation error covariance $\sigma_{o}^{2}$. From Fig. 4 it follows that $\sigma_{b}^{2}$ is equal to $2.9,2.1$, and $2.4^{\circ} \mathrm{C}^{2}$ for minimum, mean, and maximum temperature, while $\sigma_{o}^{2}$ is equal to $1.5,0.8$, and $1.1^{\circ} \mathrm{C}^{2}$ for minimum, mean and maximum temperature.

Figure 4 suggests that the OI analysis well represents observations because: (a) it gives more (less) weight to observations (background) because $\sigma_{o}^{2}$ is about half of $\sigma_{b}^{2}$; and (b) the correlation of the innovation covariance at long distance transports the observation far from the corresponding station.

Once observation and background error covariances are determined, the matrices $\mathbf{R}$ and $\mathbf{B}$ are easily formed for each parameter. $\mathbf{R}$ is a $p \times p$ diagonal matrix whose elements are all equal to $\sigma_{o}^{2}$. $\mathbf{B}$ is an $n \times n$ matrix whose element $i j$ is the value of the polynomial fitting, reported in Fig. 4, computed for the distance between grid points $i$ and $j$.

It should be noticed that the $\mathbf{B}$ matrix is specified in a different way compared to other studies (see Myrick et al., 2005; Tyndall et al., 2010 and references therein), which explicitly introduce the horizontal $(R)$ and vertical $\left(R_{z}\right)$ decorrelation distances and assume an exponential decrease of the background correlation error with distance. There are two 

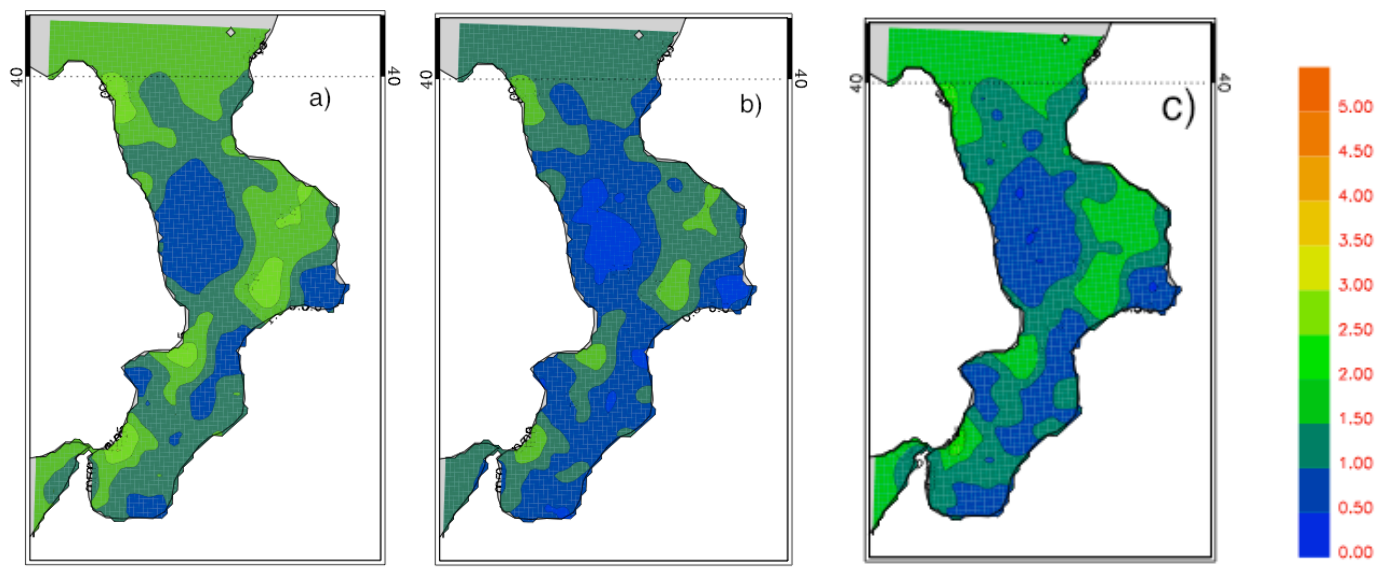

Fig. 5. OI analysis variance for minimum (panel a), mean (panel b) and maximum (panel c) temperature averaged over the whole period.

main reasons for this choice: (a) considerable research has shown that analysis approaches that directly estimate the spatial relationships between background errors are superior to those that specify them a priori (Kalnay, 2003); and (b) using horizontal and vertical decorrelation distances introduces a subjective choice of their values. This choice can be tuned for the specific application at hand to obtain more reliable analyses, though it might not be the right choice for other circumstances. This paper presents a general-purpose analysis algorithm for temperature over Calabria and it is not targeted for a specific application.

The proposed approach could produce unrealistic analyses for particular areas and meteorological phenomena like cold air confined to a side of a mountain or radiation inversions in mountain valleys. Such errors can be reduced using more computationally expensive techniques that estimate rather than specify the $\mathbf{B}$ matrix, such as ensemble Kalman filters.

Among other factors, the observations density is a crucial aspect of the analyses described above (hereafter also referred as OI analysis). It is expected that the larger the number of stations the lower the observational representative error and the higher the OI analysis quality. ${ }^{3}$ In this paper it is assumed that Calabria is a data-rich region for temperature so that the OI analysis is close to the unknown truth (Kistler, 2001). So, comparing the forecast with the analysis gives a good representation of the forecast error.

This assumption may raise doubts for the verification of the first-day forecast, whose error may be sizeably reduced by the fact that analyses use the first-day forecast as background field and that $\mathrm{OI}$ tends to minimize the error between the background and observations. This is not the case because, in this paper, the OI analysis error is also quantified. In other words, the study quantifies not only the forecast er-

\footnotetext{
3 The OI analysis quality can be estimated exactly by computing the analysis error in respect to the unknown truth, as shown later.
}

ror compared to the analysis but also the analysis error from the unknown truth, and the forecast error is estimated unambiguously.

To quantify the OI analysis error associated with each variable considered, the analysis variance is also calculated by means of the diagonal elements of the $\mathbf{P}_{a}$ matrix (Kalnay, 1993). The precision matrix is a $n \times n$ matrix given by:

$\mathbf{P}_{\mathrm{a}}=\left(\mathbf{I}_{n}-\mathbf{W H}\right) \mathbf{B}$,

where $\mathbf{I}_{n}$ is an $n$-dimension identity matrix.

Figure 5a, b, and c show the analysis variance for minimum, mean, and maximum temperature, respectively, averaged over the whole period. ${ }^{4}$ The OI analysis error associated with each variable considered (mean, maximum and minimum temperature) is given by the root square of the corresponding field reported in Fig. 5. As expected, the OI analysis error depends on the observation density: it is lower where observations are denser and it is larger in data void regions, namely the eastern flank of the Sila and northern Calabria. The error for mean temperature is the lowest because the two data sources involved in the OI analysis, i.e., the background and measurements, have a lower RMSE compared to other parameters (see Fig. 3 for $r=0$ ).

In the remainder of this paper, OI analyses are used to quantify the forecast error for two main reasons: (a) they do not suffer from representative error; and (b) the forecast error can be quantified unambiguously.

Nevertheless, OI analyses are also compared with spatially interpolated observational analyses (hereafter SI analyses) to: (a) show some aspects of the OI algorithm by comparing its performance in different conditions; and (b) study the

\footnotetext{
4 The precision matrix varies from day to day because of the diurnal dependence of the $\mathbf{H}$ operator. However, the daily dependence of $\mathbf{P}_{\mathrm{a}}$ is very weak ( $<0.1^{\circ} \mathrm{C}$ from day to day) and so the precision matrix can be assumed constant.
} 

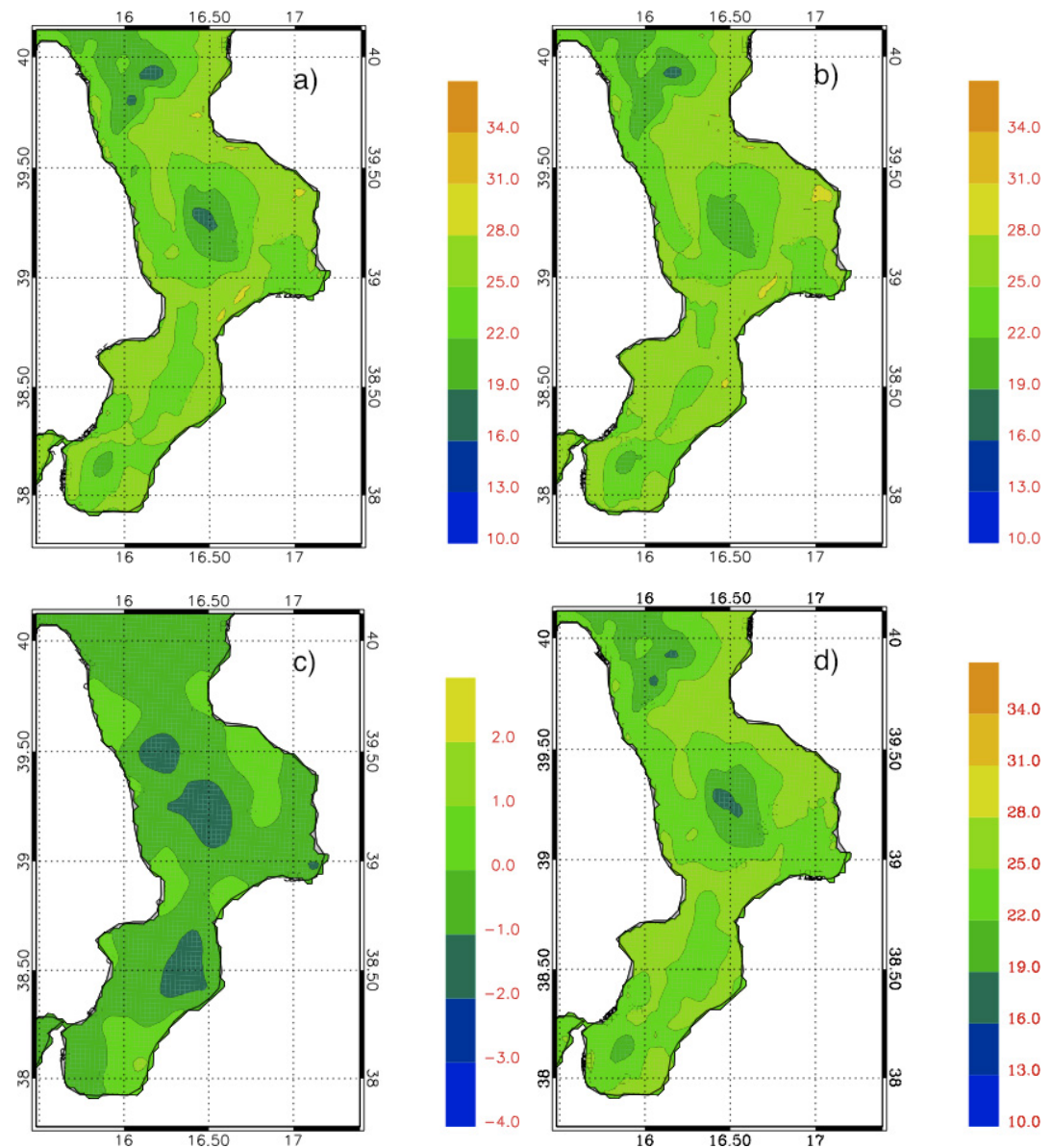

Fig. 6. (a) OI analysis for mean temperature on 18 June 2008; (b) As in (a), but for the background field; (c) Difference between the OI analysis and background; (d) SI analysis for mean temperature.

sensitivity of the statistics presented to the verifying analysis. For each day considered in the verification period, the SI analyses for mean, maximum and minimum temperature are obtained by spatially interpolating the measurements onto the RAMS grid.

The functional form of the weights used for the spatial interpolation is the square of the inverse distance and only stations inside a search radius of $40 \mathrm{~km}$ from the grid point are used in the interpolation. The spatial interpolation takes into account the difference between the station and grid point elevations through the observations' vertical temperature gradient, similarly to the $\mathbf{H} \boldsymbol{x}$ vector. The weights functional form (inverse distance and simple Kriging were also tested) and the search radius (from 10 to $60 \mathrm{~km}$ every $5 \mathrm{~km}$ ) were determined by minimizing the RMSE among the SI analyses.

Finally, because observations are taken over land only, the results and statistics of this paper are presented for the gridpoints of the third RAMS domain covered at least by $10 \%$ land (hereafter land grid points).

\section{Results}

\subsection{Forecast and analysis examples}

Two examples of forecast and analysis of mean temperature are discussed to show how the analysis system works. The cases refer to a rapid temperature increase (18 June) and to a rapid temperature decrease (15 September) over Calabria. The first case shows a good agreement between the background and the analysis fields, and is an example of a good RAMS first-day forecast. The second case was not well predicted by the model and therefore the background and analysis differ by several degrees. For both cases the synoptic scale environment is briefly introduced (not shown).

The events of 18 June followed three days of sea level pressure rise over the Ionian Sea. The increase was less pronounced on 15 and 16 June $\left(0.5 \mathrm{hPad}^{-1}\right.$ on average between Calabria and Greece) and more pronounced on 17 June $\left(1 \mathrm{hPa} \mathrm{d}^{-1}\right.$ on average between Calabria and Greece). Meanwhile, at $500 \mathrm{hPa}$, a geopotential ridge expanded from North Africa toward the Central Mediterranean. The establishment 

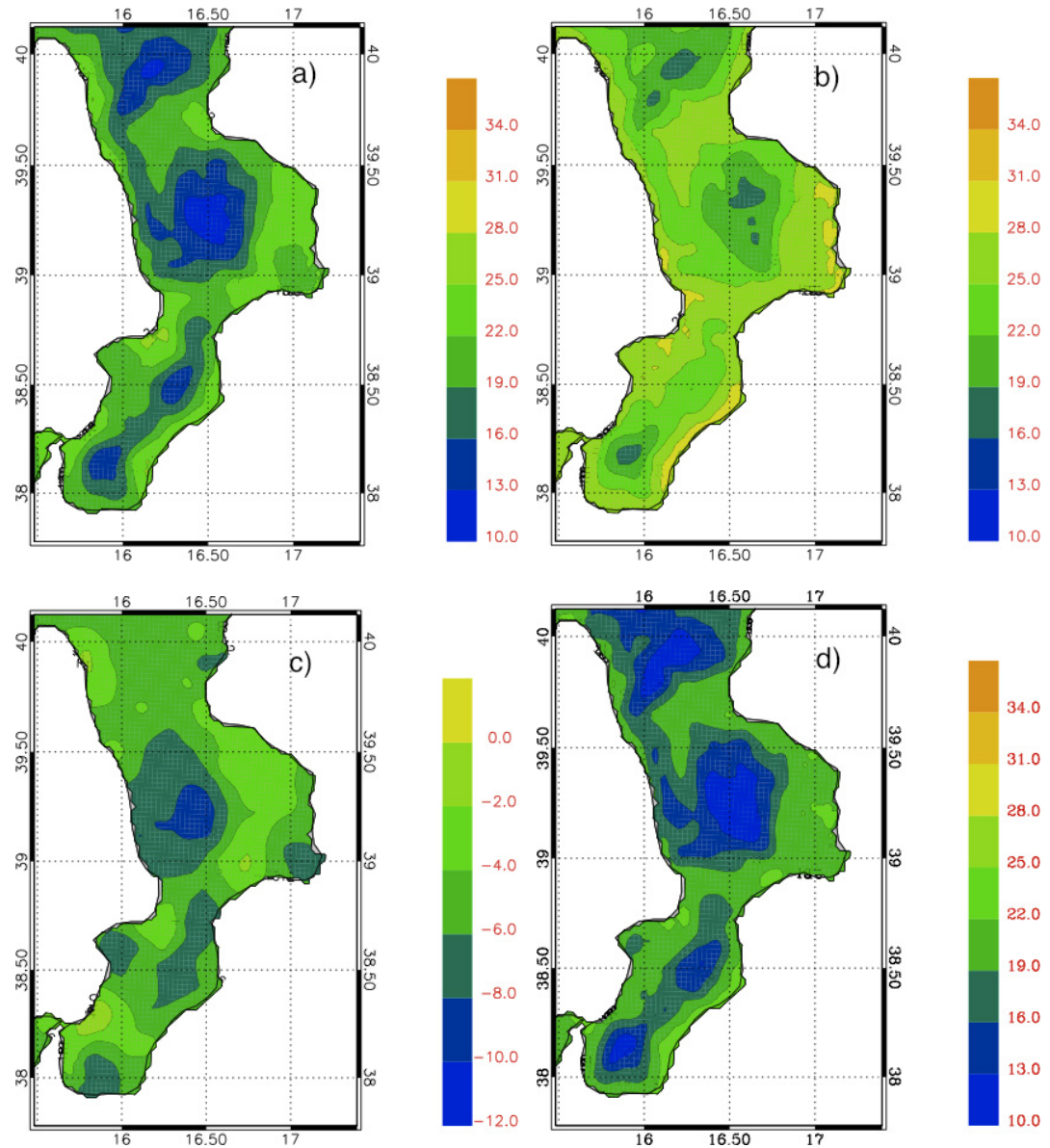

Fig. 7. As in Fig. 6, but for 15 September 2008.

of the high-pressure pattern over the Central Mediterranean determined several days of fair weather over Calabria without synoptic-scale cyclones affecting the area. The increase in the sea level pressure over the Ionian Sea produced a westeast positive pressure gradient in the Central Mediterranean and warm advection from North Africa toward Calabria. The synoptic-scale evolution led to a rapid increase in the surface temperature over the region between 15 and 18 June $\left(5^{\circ} \mathrm{C}\right.$ for the average temperature).

Figure $6 \mathrm{a}-\mathrm{c}$ show the OI analysis, the background and the difference between the two fields for the mean temperature on 18 June. The model well represents the warming over the region because the difference between the background and analysis fields is almost everywhere between -1 and $1^{\circ} \mathrm{C}$. Nevertheless, over the Sila plateau, at the northern-end of the Crati valley, and over Serre, differences are between 1 and $2{ }^{\circ} \mathrm{C}$ (analysis colder than background).

The rapid temperature increase over Calabria is confirmed by the low ACC value (see next section for details) of the second day of a 48-h persistence forecast (day 12 in Fig. 9). The value of ACC for 18 June is 0.97 for the RAMS second-day forecast and -0.84 for the second day of a 48 -h persistence forecast.
Figure $6 \mathrm{~d}$ shows the SI analysis for 18 June. Given the small differences between the two observational gridded fields plotted in Fig. 6a and d, it can be stated that the OI analysis is able to well represent measurements. This is shown, for example, by the local temperature minimum over the Sila plateau, which is present in both analyses but not in the background field, and by the temperature field over the Serre, which is lower than the background in both analyses.

The second case refers to the passage of a synopticscale storm over Calabria and the central Mediterranean, which persisted from 14 to 16 September. The storm left considerable precipitation over the region and the sky was overcast. Rainfall was noticeably abundant on 14 September, when 19 rain gauges recorded more than $50 \mathrm{~mm} \mathrm{~d}^{-1}$. The rainfall averages for all rain gauges were 40, 8.5, and $6.5 \mathrm{~mm}$, on 14,15 , and 16 September, respectively.

Temperature decreased during the storm (see also Fig. 4 in Federico et al., 2010), which marked the change in climate regime from summer to fall. The average temperature over Calabria decreased from $23.5^{\circ} \mathrm{C}$ on 13 September to $15.7^{\circ} \mathrm{C}$ on 18 September. The storm was not well forecast by RAMS on 15 September in terms of precipitation amount, cloud coverage, and temperature decrease. Figure $7 a, b$, and c show the 

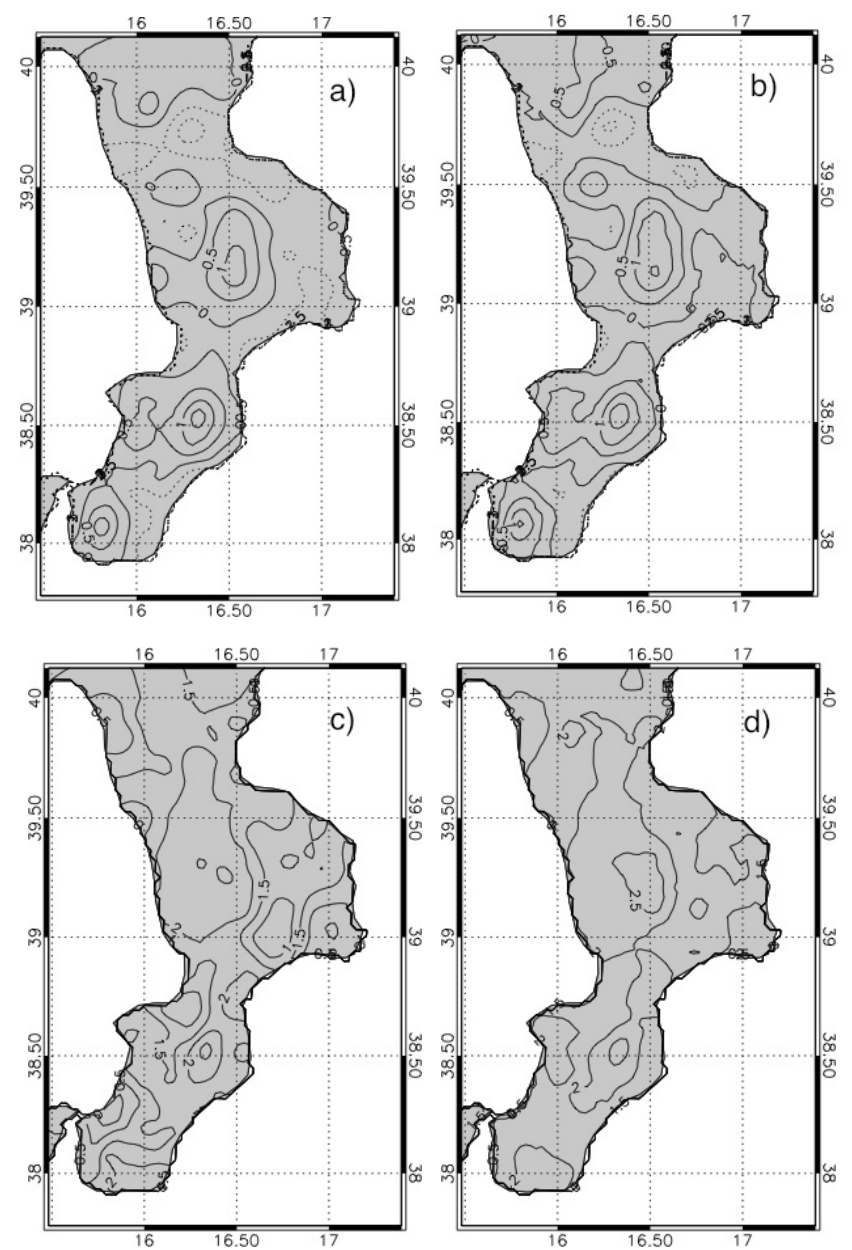

Fig. 8. (a) Mean temperature bias for the first-day forecast; (b) As in Fig. 8a, but for the fourth-day forecast; (c) Mean temperature RMSE for the first-day forecast; (d) As in Fig. 8c, but for the fourthday forecast. Contours drawn at interval of $0.5^{\circ}$.

OI analysis, the background field, and the difference between these two fields for mean temperature on 15 September. Differences are between -10 and $-8^{\circ} \mathrm{C}$ over the Sila plateau and the absolute value of the difference is larger than $4{ }^{\circ} \mathrm{C}$ for most grid points.

The background field in Fig. $7 \mathrm{~b}$ is obtained from the firstday forecast issued on 15 September. Noticeably, the forecast missed the event also on 14, 16, and 17 September, as confirmed by the low ACC values for the second-day RAMS forecast (days 100-103 of Fig. 9). The second day of a 48-h persistence forecast was better than the RAMS second-day forecast for 17 September (day 103 of Fig. 9; ACC is 0.90 for persistence and -0.74 for RAMS).

Figure 7d shows the 15 September SI analysis. Differences between the two analyses are larger compared to those obtained on 18 June and the OI analysis is warmer than the SI analysis as a consequence of using the RAMS temperature as the background field. The RAMS error (Fig. 7c) is clearly

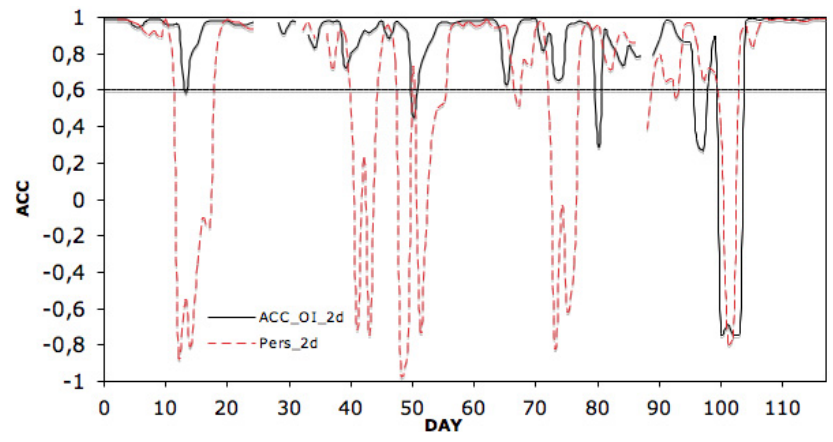

Fig. 9. Mean temperature ACC computed respect to OI analyses for RAMS second-day forecast (black solid line) and for the second day of a 48-h persistence forecast (dashed line) based on OI analyses. Days 0-24 are June, days 25-55 are July, days 56-86 are August and days 87-116 are September. RAMS forecasts and analyses are not available for five days (gaps in the solid and dashed lines at the beginning of July and September).

underestimated compared to the true error for 15 September, but the forecast error contributes to increase the analysis error for the whole period (Fig. 5a-c). For 15 September, using the RAMS first-day forecast as the background field in OI reduces the forecast error but this effect is offset by the increase in the analysis error.

It must be pointed out that the analysis errors in Fig. 5a-c are estimated for the whole period because the background matrix is constant and does not account for the "error of the day". As a result, it follows that for the 15 September event the analysis error is underestimated, whereas for the 18 June event it is overestimated. For the whole period the "overestimation" and "underestimation" compensate. While more advanced techniques take this problem into account, at present OI analysis is the best technique for Calabria.

Figures 6 and 7 are representative of the OI analysis in two different situations at the extremes of the RAMS forecast performance. On 18 June, the analysis corrects the background field at local scale. Corrections are due to the misforecast of the cloud coverage induced by local circulations, or to the misforecast of local circulation characteristics such as timing, direction, and intensity (De Leo et al., 2008). On 15 September, the analysis sizeably corrects the background field over the whole region, as a result of the poor forecast, and superimposes to this gross correction additional corrections accounting for local effects.

\subsection{Cumulative statistics}

This section shows cumulative statistics of bias and RMSE to quantify the forecast error and common forecast tendencies, while ACC (Wilks, 2006) statistics are used to compare the RAMS forecast with persistence. In the context of forecast verification, cumulative statistics are necessary to reduce the verification dimensionality (Murphy, 1991). Statistics are 
Table 2. Bias, MAE, and RMSE, computed with respect to the OI analyses, averaged for land grid points. Rows show the result for each forecast day. Min, med, and max refers to minimum, mean and maximum temperature, respectively. The analysis error is shown only for the first day and is equal for all days. Values into parentheses show the statistics computed with respect to SI analyses.

\begin{tabular}{cccccccccc}
\hline & $\begin{array}{c}\text { Bias } \\
\text { min }\end{array}$ & $\begin{array}{c}\text { Bias } \\
\text { med }\end{array}$ & $\begin{array}{c}\text { Bias } \\
\text { max }\end{array}$ & $\begin{array}{c}\text { MAE } \\
\text { min }\end{array}$ & $\begin{array}{c}\text { MAE } \\
\text { med }\end{array}$ & $\begin{array}{c}\text { MAE } \\
\text { max }\end{array}$ & $\begin{array}{c}\text { RMSE } \\
\text { min }\end{array}$ & $\begin{array}{c}\text { RMSE } \\
\text { med }\end{array}$ & $\begin{array}{c}\text { RMSE } \\
\text { max }\end{array}$ \\
\hline 1-D & $\begin{array}{c}-0.2 \pm 1.2 \\
(-0.2)\end{array}$ & $\begin{array}{c}0.1 \pm 0.9 \\
(0.2)\end{array}$ & $\begin{array}{c}0.2 \pm 1.1 \\
(0.4)\end{array}$ & $\begin{array}{c}1.3 \pm 1.2 \\
(1.9)\end{array}$ & $\begin{array}{c}1.2 \pm 0.9 \\
(1.5)\end{array}$ & $\begin{array}{c}1.4 \pm 1.1 \\
(1.9)\end{array}$ & $\begin{array}{c}1.8 \pm 1.2 \\
(2.6)\end{array}$ & $\begin{array}{c}1.6 \pm 0.9 \\
(2.2)\end{array}$ & $\begin{array}{c}2.0 \pm 1.1 \\
(2.7)\end{array}$ \\
\hline 2-D & -0.5 & 0.2 & 0.6 & 1.5 & 1.2 & 1.5 & 1.9 & 1.8 & 2.4 \\
& $(-0.6)$ & $(0.4)$ & $(0.8)$ & $(2.0)$ & $(1.6)$ & $(2.0)$ & $(2.6)$ & $(2.3)$ & $(2.8)$ \\
\hline 3-D & -0.5 & 0.2 & 0.5 & 1.6 & 1.3 & 1.6 & 2.0 & 1.9 & 2.4 \\
& $(-0.6)$ & $(0.4)$ & $(0.8)$ & $(2.0)$ & $(1.6)$ & $(2.0)$ & $(2.7)$ & $(2.3)$ & $(2.9)$ \\
\hline 4-D & -0.6 & 0.3 & 0.5 & 1.6 & 1.3 & 1.8 & 2.0 & 1.9 & 2.6 \\
& $(-0.7)$ & $(0.4)$ & $(0.9)$ & $(2.1)$ & $(1.7)$ & $(2.2)$ & $(2.7)$ & $(2.4)$ & $(3.1)$ \\
\hline
\end{tabular}

computed for summer 2008 (112 runs) and, while one season is not sufficient to draw final conclusions, they give a first assessment of model performance.

Figure 8 shows the bias (Fig. 8a, b) and RMSE (Fig. 8c, d) in mean temperature calculated for the whole forecast period (6 June-30 September), for the first and fourth forecast days, which show the best and the worst performance, respectively. The bias is computed for each grid point as the average of the difference between the forecast and the OI analysis for the whole period. The bias is positive over the main mountain peaks and is negative for lowland and coastal areas. The absolute value of the bias increases between the first and fourth forecast days, and the areas with positive bias are more widespread for the fourth day, denoting a forecast drift toward warmer temperatures compared to the analysis with increasing forecasting time. For mean temperature, more than $98 \%$ of the grid points show an absolute bias less than $1^{\circ} \mathrm{C}$ for all four days.

Bias patterns of minimum and maximum temperature are similar to those reported in Fig. 8a and b, but with associated larger bias (not shown).

The RMSE of mean temperature is shown in Fig. 8c and d. It is computed for each grid point $i$ as:

$\operatorname{RMSE}_{i}=\sqrt{\frac{\sum_{J=1}^{N}\left(T_{A_{J}}^{i}-T_{F_{J}}^{i}\right)^{2}}{N}}$,

where $T_{A J}^{i}$ is the OI analysis for the $i$-th grid point and for the $J$-th day, $T_{F J}^{i}$ is the forecast for the same day and for the same grid point, and $N$ is the number of simulations (112).

RMSE is larger than $2^{\circ} \mathrm{C}$ in central Calabria while RMSE is lower than $1{ }^{\circ} \mathrm{C}$ over the eastern flank of the Sila plateau. By comparing Fig. 8c and d, the increase in the RMSE with forecasting time is apparent. In particular, RMSE is one-half degree larger over the eastern flank of the Sila plateau and over the southern part of the Lamezia Terme and Gioia Tauro plains.
RMSE patterns for minimum and maximum temperature are similar to those reported in Fig. 8c and d, but errors are larger (not shown).

Figure 8c shows the effect of using the RAMS first-day forecast as the background field in the OI analyses. The decrease in the RMSE in northern Calabria and on the eastern flank of Sila is caused by the larger weight that the analysis algorithm gives to the background in data void areas. So, the error decrease is not caused by a better agreement between the RAMS forecast and observations, rather, it is a consequence of the lack of measurements. However, the OI algorithm accounts for this effect because the analysis error comparatively increases in these areas (Fig. 5a-c) and analyses are less reliable.

To quantify the forecast error for all (land) grid points of the third RAMS domain, Table 2 shows the values of the bias, mean absolute error (MAE) and RMSE averaged over the land grid points. Analysis error is used to quantify the uncertainty in the estimate of the forecast error. It is given by the land grid-points average of the square root of Fig. 5a-c. The first-day forecast has a small bias. ${ }^{5}$ For other forecast days, minimum temperature has a negative bias (the forecast is colder than the analysis), while maximum temperature shows a positive bias (the forecast is warmer than the analysis).

The largest RMSE is for maximum temperature. It increases from $2.0^{\circ} \mathrm{C}$ (first day) to $2.6^{\circ} \mathrm{C}$ (fourth day). The RMSE increases slowly during the four forecast days. This is partially determined by the season considered in this work. In summer, the weather over Calabria is rather stable (Colacino, 1992; Federico et al., 2009) and its predictability is expected to be longer than in other seasons.

\footnotetext{
${ }^{5}$ It is important to note that no methodologies were applied to correct or reduce the bias, and the bias could be considerably larger in other seasons or years. Moreover, the day-to-day bias is not negligible as shown, for example, for 15 September (previous section).
} 
Table 3. Average of the ACC for the whole period for RAMS and persistence forecasts. The seasonal average is computed as the average of the OI analyses for the period considered. Persistence is computed from OI analyses. $\mathrm{ACC}_{\min }$ columns are for minimum temperature, $\mathrm{ACC}_{\text {mea }}$ columns are for mean temperature, and $\mathrm{ACC}_{\max }$ columns are for maximum temperature. Values into parentheses show the $\mathrm{ACC}$ statistic computed using SI seasonal average and the persistence computed from SI analyses.

\begin{tabular}{llll|lll}
\hline & \multicolumn{3}{c}{$\mathrm{RAMS}$} & \multicolumn{3}{c}{ PERSISTENCE } \\
& $\mathrm{ACC}_{\min }$ & $\mathrm{ACC}_{\text {mea }}$ & $\mathrm{ACC}_{\max }$ & $\mathrm{ACC}_{\min }$ & $\mathrm{ACC}_{\text {mea }}$ & $\mathrm{ACC}_{\max }$ \\
\hline 1-D & $0.82(0.70)$ & $0.85(0.82)$ & $0.87(0.82)$ & $0.70(0.70)$ & $0.79(0.80)$ & $0.74(0.76)$ \\
\hline 2-D & $0.73(0.65)$ & $0.84(0.82)$ & $0.84(0.80)$ & $0.54(0.58)$ & $0.60(0.63)$ & $0.56(0.59)$ \\
\hline 3-D & $0.71(0.63)$ & $0.83(0.81)$ & $0.81(0.78)$ & $0.47(0.49)$ & $0.54(0.56)$ & $0.49(0.51)$ \\
\hline 4-D & $0.70(0.62)$ & $0.82(0.80)$ & $0.78(0.77)$ & $0.42(0.45)$ & $0.53(0.54)$ & $0.47(0.49)$ \\
\hline
\end{tabular}

Table 2 also shows the results of the comparison between the forecast and SI analysis to quantify the statistics' sensitivity to the verifying analysis. The error increases slowly with forecasting time and RMSE values are $0.5-0.8^{\circ} \mathrm{C}$ larger than for OI analysis. The error computed with respect to SI analyses is likely an overestimation of the true error because measurement errors are ignored. Nevertheless, the difference between the two statistics is lower than the analysis error.

The usefulness of the forecast for all days is confirmed by the ACC analysis. ACC (Wilks, 2006) is a commonly used measure of association between gridded fields (the forecast and observational analysis fields in this paper). To compute ACC, the seasonal average is subtracted from each field to draw attention to how well the forecast captures the day-today variability. In this paper, the seasonal average is given by the average of the OI analyses computed for the whole period. The threshold value for a skilful forecast is 0.5 , however it is a common practice to use the 0.6 threshold to define a useful forecast.

Figure 9 shows the ACC comparison between the secondday RAMS forecast and the second day of a 48-h persistence forecast for mean temperature. The second day is chosen because it does not show the best or the worst performance, so provides a good representation of the whole forecast behaviour. There is large day-to-day variability and the RAMS forecast is usually better (70\% of the cases) than persistence. This behaviour is also shown by minimum (69\%) and maximum (75\%) temperature second-day forecasts (not shown). As discussed in the previous section, the RAMS forecast was particularly poor for four consecutive days in September (days 100-103, from 14 to 17 September). The second-day RAMS forecast is useful in $90 \%$ of cases for mean temperature, in $76 \%$ of cases for minimum temperature, and in $92 \%$ of cases for maximum temperature. So, despite the RMSE of maximum temperature being the largest, the RAMS forecast better follows the day-to-day variability of this parameter. Similar considerations apply to other forecast days (not shown).
To show the effect of using the RAMS first-day forecast as the background field in the OI analysis, the ACC is computed using both OI and SI seasonal averages (ACC_OI and ACC_SI, respectively).

Table 3 shows the ACC average computed for the whole period for RAMS (both ACC_OI and ACC_SI). In this table the 1-D row refers to the first day RAMS forecast and to the 24-h forecast of a one-day persistence forecast, and similarly for other days.

The ACC is larger than 0.6 for each parameter and forecast day. The RAMS forecast is always better than persistence, especially for days two to four. Persistence is useful for the first day and for mean temperature of the second day; nonetheless, the ACC for the RAMS fourth-day forecast is still better than the one-day persistence forecast for ACC_OI.

The previous statement is not valid for the ACC_SI minimum temperature and Table 3 shows a decrease in the ACC performance for minimum temperature when the SI seasonal average is used. In particular: (a) differences between 1-D ACC_OI and 1-D ACC_SI are much larger for minimum temperature than for other parameters $(0.12,0.03$, and 0.05 for minimum, mean, and maximum temperature, respectively); and (b) the ACC_OI decrease between the first- and secondday forecast is larger for minimum temperature compared to others parameters. Both results show the effect of using the RAMS first-day forecast as the background field in the OI analysis, because minimum temperature has the largest representative error (Fig. 4). As a consequence, compared to other parameters, OI analyses give a larger weight to the background field for minimum temperature, which causes the two behaviours in the ACC_OI and ACC_SI statistics mentioned above. Nevertheless, the RAMS forecast is useful for minimum temperature when the SI seasonal average is used to compute ACC. The persistence forecast performance is expected to decrease in other seasons.

Finally, differences between ACC_OI and ACC_SI provide an estimation of the error associated with these statistics. 


\section{Conclusions}

Beginning in the June 2008, a high-resolution $(2.5 \mathrm{~km})$ temperature forecast has been issued daily at CRATI/ISAC-CNR out to four days for the Calabria peninsula (southern Italy). This paper shows the performance of the surface minimum, mean, and maximum temperature forecasts from 6 June to 30 September 2008 (112 runs out of 117 days because the forecast was not available for five days). While it is not possible to draw final conclusions about the resulting statistics because of the brevity of the analysis period, it must be stressed that: (a) summer is the most important season for open field agriculture in the country, and farmers are among the final users of the forecast; (b) the study introduces the analysis system for future reference.

The subgrid-scale variability in weather and inadequate ground truth, because of both instrumental and representative errors, significantly complicate the forecast verification, especially in complex orography. To cope with these difficulties, surface analyses of minimum, mean, and maximum temperature have been prepared at $2.5 \mathrm{~km}$ resolution since June 2008. The analysis algorithm, which uses the RAMS first-day forecast as the background field, is based on Optimal Interpolation and uses data from 87 thermometers. Measurements are (objectively) quality controlled to reject data that show gross differences with nearby stations.

The analysis error, which quantifies the difference between the OI analysis and the unknown truth, is introduced to show the effect of using the RAMS first-day forecast in the OI algorithm and to quantify the forecast error unambiguously.

A simple spatial interpolation analysis is used to show some aspects of the OI analyses and to assess the statistics' sensitivity to the verifying analysis.

Two case studies are then discussed to show the OI behaviour in different conditions. The 18 June study refers to a rapid warming of surface temperature caused by a favourable synoptic environment, namely clear-sky conditions and warm advection from North Africa toward Calabria. The case was well predicted by RAMS and the difference between the background and OI analysis of mean temperature was between $-1{ }^{\circ} \mathrm{C}$ and $1{ }^{\circ} \mathrm{C}$ for most grid points. The difference is larger (between 1 and $2{ }^{\circ} \mathrm{C}$ ) for specific areas showing local phenomena that are not well predicted by the model, such as local circulation characteristics. Comparing OI and SI analyses for 18 June shows the ability of the OI analysis to well represent measurements.

The 15 September case study refers to the passage of a synoptic-scale storm that persisted over Calabria from 14 to 16 September. During this period, the sky was overcast and rain abundant, especially on 14 September. A considerable temperature decrease accompanied this storm, which was not well predicted by the model, and differences between the background and analysis are larger than $4{ }^{\circ} \mathrm{C}$ (locally larger than $\left.8^{\circ} \mathrm{C}\right)$.
Comparing OI and SI analyses shows a less satisfactory result (the worst of the whole period) for OI and the forecast error is underestimated compared to the true error. The forecast error underestimation is compensated for by an increase in the analysis error because days with larger errors are those contributing more to the increase in the analysis error. Nevertheless, assuming a constant background error produces an underestimation of the analysis error for 15 September. The reverse occurs on 18 June and the two effects compensate considering the whole period.

Measure-oriented cumulative statistics are used to reduce the forecast verification dimensionality and to elucidate common forecast tendencies.

The forecast shows a drift toward cold bias for minimum temperature $\left(-0.6^{\circ} \mathrm{C}\right.$ for the fourth day), and a drift toward warm bias for mean $\left(0.3^{\circ} \mathrm{C}\right.$ for the fourth day) and maximum $\left(0.5^{\circ} \mathrm{C}\right.$ for the fourth day) temperatures.

The RMSE shows a slow increase from the first- to the fourth-day forecast. In particular, RMSE increases from 1.8 to $2.0^{\circ} \mathrm{C}$ for minimum temperature, from 1.6 to $1.9^{\circ} \mathrm{C}$ for mean temperature, and from 2.0 to $2.6^{\circ} \mathrm{C}$ for maximum temperature. The small error increase with forecasting time is, at least partially, caused by the stability of the weather in the area during summer. Statistics' errors are quantified by the OI analysis error.

To show the statistics' sensitivity to the verifying analysis, cumulative statistics are computed with respect to SI analyses as well. Even if SI statistics are likely an overestimation of the true error, because they do not consider the observational errors, the OI analysis error is larger than the difference between statistics computed with respect to OI and SI analyses.

The RMSE spatial distribution shows the largest values for the Crati valley and for the western part of Sila, and the lowest values for northern Calabria and for the eastern flank of Sila. The RMSE spatial distribution is similar for all parameters and for all forecast days. The decrease in the RMSE in northern Calabria and on the eastern flank of Sila is caused by the larger weight that the analysis algorithm gives to the background field in data void areas. At the same time, the analysis error increases for these areas, compensating for the forecast error decrease, and unambiguously defining the forecast error.

By performing the anomaly correlation analysis, the usefulness of the RAMS forecast compared to the persistence forecast is shown. The latter shows a good performance because of the stability of weather patterns over Calabria in summer. The second-day forecast is considered as representative of the whole forecast because its score is between the best (first-day) and the worst (fourth-day) scores. Assuming the 0.6 threshold to define a useful forecast, the second-day RAMS forecast is useful in $90 \%$ of cases for mean temperature, in $76 \%$ of cases for minimum temperature, and in $92 \%$ of cases for maximum temperature, when the OI seasonal average is used to compute ACC. 
Comparing ACC_OI and ACC_SI average values for the whole period shows that RAMS forecast is always better than persistence. The RAMS fourth-day forecast is better than the one-day persistence forecast when the ACC_OI is considered, while this is not verified for minimum temperature for the ACC_SI.

A decrease in the ACC_SI performance is noticed for minimum temperature compared to that for mean and maximum temperatures. Because SI analyses are given by the spatial interpolation of observations, this decrease does not reflect poorer model performance, but is caused by the larger representative error of temperature observations in stable boundary layer conditions. The difference between the ACC_OI and ACC_SI statistics gives an estimate of the error associated with these statistics.

Acknowledgements. This work was partially funded by the project "MAPVIC - Modellistica Agrometeorologica di Precisione per la Viticoltura Calabrese" funded by the Calabria Region. ARPACAL is acknowledged for the use of the regional network data. I would like to thank both reviewers for their precise and useful comments.

Edited by: M.-C. Llasat

Reviewed by: two anonymous referees

\section{References}

Brier, G. W. and Allen, R. A.: Verification of weather forecasts, Compendium of Meteorology, T. F. Malone, Ed., Amer. Meteor. Soc., 841-848, 1951.

Chen, C. and Cotton, W. R.: A One-Dimensional Simulation of the Stratocumulus-Capped Mixed Layer, Bound.-Lay. Meteorol., 25, 289-321, 1983.

Colacino, M.: Mediterranean Meteorology, in: Proceedings NATOASI, edited by: Charnock, H., Reports in Meteorology and Oceanography, 40, 1-38, 1992.

Colacino, M., Conte, M., and Piervitali, E.: Elementi di climatologia della Calabria, IFA-CNR, Rome, 197 pp., 1997.

Cotton, W. R., Pielke, R. A., Sr., Walko, R. L., Liston, G. E., Tremback, C. J., Jiang, H., McAnelly, R. L., Harrington, J. Y., Nicholls, M. E., Carrio, G. G., and McFadden, J. P.: RAMS 2001: Current satus and future directions, Meteor. Atmos. Phys., 82, 5-29, 2003.

De Leo, L., Federico, S., Sempreviva, A. M., Pasqualoni, L., Avolio, E., and Bellecci, C.: Study of the development of the sea breeze and its micro-scale structure at a coastal site using a Multi-Tone Sodar system, Earth Environ. Sci., 1, 1-8, doi:10.1088/17551307/1/1/012054, 2008.

Federico, S., Avolio, E., Pasqualoni, L., and Bellecci, C.: Atmospheric patterns for heavy rain events in Calabria, Nat. Hazards Earth Syst. Sci., 8, 1173-1186, doi:10.5194/nhess-8-1173-2008, 2008.

Federico, S., Avolio, E., Pasqualoni, L., De Leo, L., Sempreviva, A. M., and Bellecci, C.: Preliminary results of a 30-year daily rainfall data base in southern Italy, Atmos. Res., 94, 4, 641-651, doi:10.1016/j.atmosres.2009.03.00., 2009.

Federico, S., Pasqualoni, L., De Leo, L., and Bellecci, C.: A study of the breeze circulation during summer and fall 2008 in Calabria, Italy, Atmos. Res., 97, 1-2, 1-13, doi:10.1016/j.atmosres.2010.02.009., 2010.

Kalnay, E.: Atmospheric Modeling, Data Assimilation and Predictability, Cambridge University Press, 341 pp., 2003.

Kistler, R., Collins, W., Saha, S., White, G., Woollen, J., Kalnay, E., Chelliah, M., Ebisuzaki, W., Kanamitsu, M., Kousky, V., van den Dool, H., Jenne, R., and Fiorino, M.: The NCEP/NCAR 50Year reanalysis: monthly means CD-ROM and documentation, B. Am. Meteorol. Soc., 82, 247-268, 2001.

Joliffe, I. T. and Stephenson, D. B.: Forecast Verification: A Practitioner's Guide in Atmospheric Science, Wiley, New-York, 240 pp., 2003.

Lönnberg, P. and Hollingsworth, A.: The statistical structure of short-range forecast errors as determined from radiosonde data. Part II: The covariance of height and wind errors, Tellus, 38A, 137-161, 1986.

Mass, C. F., Albright, M., Ovens, D., Steed, R., Maciver, M., Grimit, E., Eckel, T., Lamb, B., Vaughan, J., Westrick, K., Storck, P., Colman, B., Hill, C., Maykut, N., Gilroy, M., Ferguson, S. A., Yetter, J., Sierchio, J. M., Bowman, C., Stender, R., Wilson, R., and Brown, W.: Regional Environmental Prediction Over the Pacific Northwest, B. Am. Meteor. Soc., 84 (10), 1353-1366, 2003.

Mason, S. J. and Weigel, A. P.: A Generic Forecast Verification Framework for Administrative Purposes, Weather Rev., 137, 331-349, 2009.

Mellor, G. and Yamada, T.: Development of a Turbulence Closure Model for Geophysical Fluid Problems, Rev. Geophys. Space Phys., 20, 851-875, 1982.

Molinari, J. and Corsetti, T.: Incorporation of cloud-scale and mesoscale down-drafts into a cumulus parametrization: results of one and three-dimensional integrations, Mon. Weather Rev., 113, 485-501, 1985.

Murphy, A. H.: Forecast verification: Its complexity and dimensionality, Mon. Weather Rev., 119, 1590-1601, 1991.

Murphy, A. H.: What is a good forecast? An essay on the nature of goodness in weather forecasting, Weather Forecast., 18, 281293, 1993.

Myrick, D. T. and Horel, J. H.: Verification of surface temperature from the National Digital Forecast Database over the western United States, Weather Forecast., 21, 869-892, 2006.

Myrick, D. T., Horel, J. D., and Lazarus, S. M.: Local adjustment of the background error correlation for surface analyses over complex terrain, Weather Forecast., 20, 149-160, 2005.

Pielke, R. A: Mesoscale Meteorological Modeling, Academic Press, San Diego, 677 pp., 2002.

Press, W. H., Teukolsky, S. A., Vetterling, W. T., and Flannery, B. P.: Numerical recipes in Fortran 77, second ed., Cambridge University Press, Cambridge, 992 pp., 1992.

Sela, J. G.: Spectral modelling at the National Meteorological Center, Mon. Weather Rev., 108, 1279-1292, 1980.

Sela, J. G.: The NMC Spectral Model, NOAA Tech. Rep. NWS-30, 36 pp., 1982.

Simpson, J. E.: Sea breeze and local winds, Cambridge University Press, Cambridge, 224 pp., 1994.

Smagorinsky, J.: General circulation experiments with the primitive equations. Part I, The basic experiment, Mon. Weather Rev., 91, 99-164, 1963. 
Tyndall, D. P., Horel, J. D., and De Pondeca, M. S. F. V.: Sensitivity of Surface Air Temperature Analyses to Background and Observation Errors, Weather Forecast., 25, 852-865, 2010.

Walko, R. L., Cotton, W. R., Meyers, M. P., and Harrington, J. Y.: New RAMS cloud microphysics parameterization part I: the single-moment scheme, Atmos. Res., 38, 29-62, 1995.

Walko, R. L., Band, L. E., Baron, J., Kittel, T. G., Lammers, R., Lee, T. J., Ojima, D., Pielke, R. A. Sr., Taylor, C., Tague, C., Tremback, C. J., and Vidale, P. L.: Coupled Atmosphere-BiosphereHydrology Models for environmental prediction, J. Appl. Met., 39, 931-944, 2000.
Wilks, D. S.: Statistical Methods in the Atmospheric Sciences, Academic Press, 648 pp., 2006.

$\mathrm{Xu}$, Q., Wei, L., Van Tuyl, A., and Barker, E. H: Estimation of three-dimensional error covariances. Part I: Analysis of height innovation vectors, Mon. Weather Rev., 129, 2126-2135, 2001. 